I have seen her once since, and found that she was almost well. The fact that she has not reappeared shows that, in her opinion, she is practically cured.

Sir James Mackenzie Davidson, to whom, and to Dr. J. E. A. Lynham, I am greatly obliged for full notes of the treatment, says in his letter to me:-

"I may say that in every case without exception which I have treated with radium the plaques have completely disappeared leaving no scars at all. In a few cases the eye has continued irritable and injected, but the appearances characteristic of the disease have not appeared. I look upon radium as a specific for spring catarrh."

The two foregoing cases entirely corroborate Sir James's opinion.

\title{
ANOPHTHALMIA AND MICROPHTHALMIA
}

BY

D. Leighton Davies, M.S., F.R.C.S.,

ASSISTANT OPHTHALMIC SURGEON, KING EDWARD VII HOSPITAL, CARDIFF.

CONGENital malformations have always a certain amount of interest attached to them. In many parts of the body these malformations, when they interfere with the comfort and wellbeing or the usefulness of the individual, are amenable to surgical treatment. In the case of the eyeball, however, such defects are very seldom remediable. On the other hand, in this situation they are open to very close examination, so that their interest is increased. I therefore venture to add to the already long list of congenital abnormalities, so far as it concerns our own specialized region, the following five cases :-

CASE 1.-Anophthalmia.-A. W. I first saw this child in February, 1910. She was then six weeks old, and was brought to the King Edward VII Hospital, Cardiff, on account of a thick white discharge from the right orbit. From the history obtained, the following points are worthy of note.-The child was born at term; there were other children, but the numbers were not given; none of them, however, suffered from any deformities; there had been no miscarriages. The parents were not related before marriage, and there was no history of deformities existing in the relations of either parent. The mother volunteered a statement that in the second month of her pregnancy, she had a severe fright, which she thought would account for the deformity in her baby. Otherwise she was in perfect health.

The notes of the case as then seen are as follows:-

There is a muco-purulent discharge from the right orbit, which is 
small and its depth diminished, but otherwise appears to be well formed.

The lids are small and the palpebral fissure is also very small, being only 7-8 $\mathrm{mm}$. wide, and occupying the inner half of the lids. The puncta lacrimalia are both present. A few cilia are present on the upper lid only.

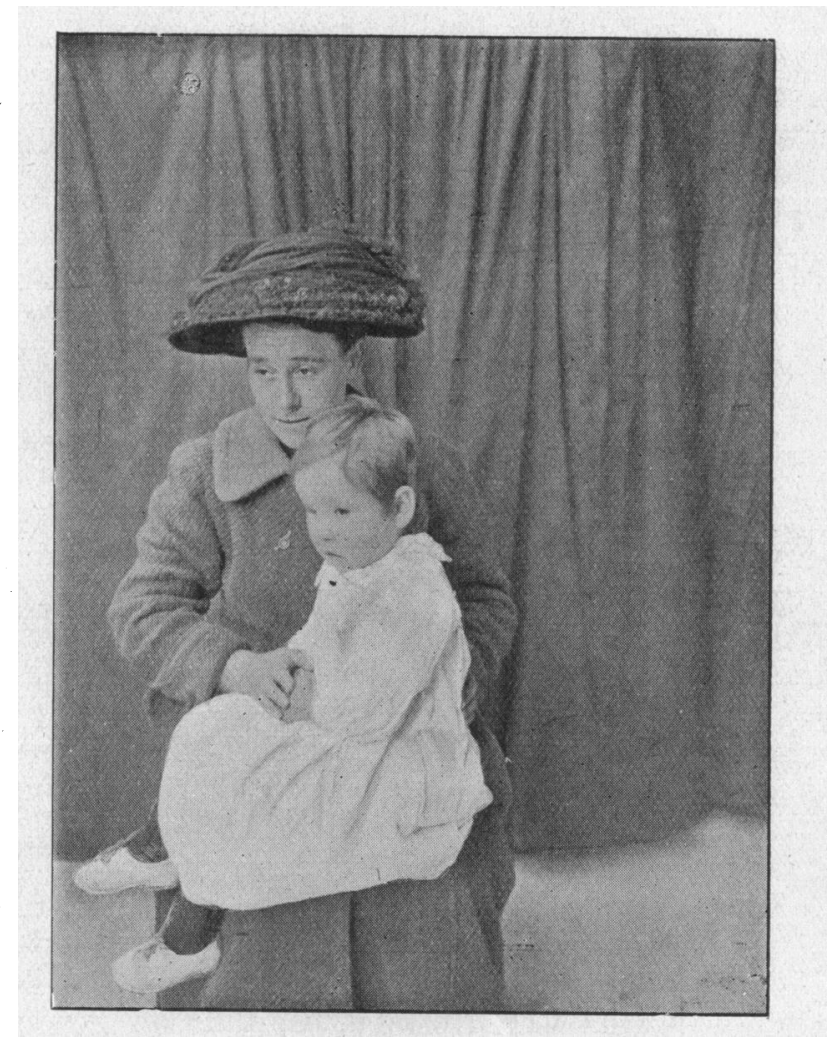

FrG. 1.

There is no eyeball in the orbit, which is however lined] with conjunctiva. This is puckered up a little at the posterior extremity, where there is a tiny nodule, scarcely the size of a pin's head. The conjunctiva moves when the left eye moves in the same. way as the socket of an eye from which the globe has been enucleated. In addition, there is marked deformity of the right external auditory apparatus. The pinna is absent, being represented by small nodules of skin and cartilage (?), behind which is a slight depression about the size of the end of a small silver probe, but which does not pass inwards. 
The face is markedly asymmetrical, the affected side being smaller than the other. When the child cries, the mouth is drawn over to the left, and there is no movement of the facial muscles on the right. There is a small nodule of skin on the right side of the neck, a little below and behind the angle of the jaw, which probably marks the position of the posterior extremity of the second

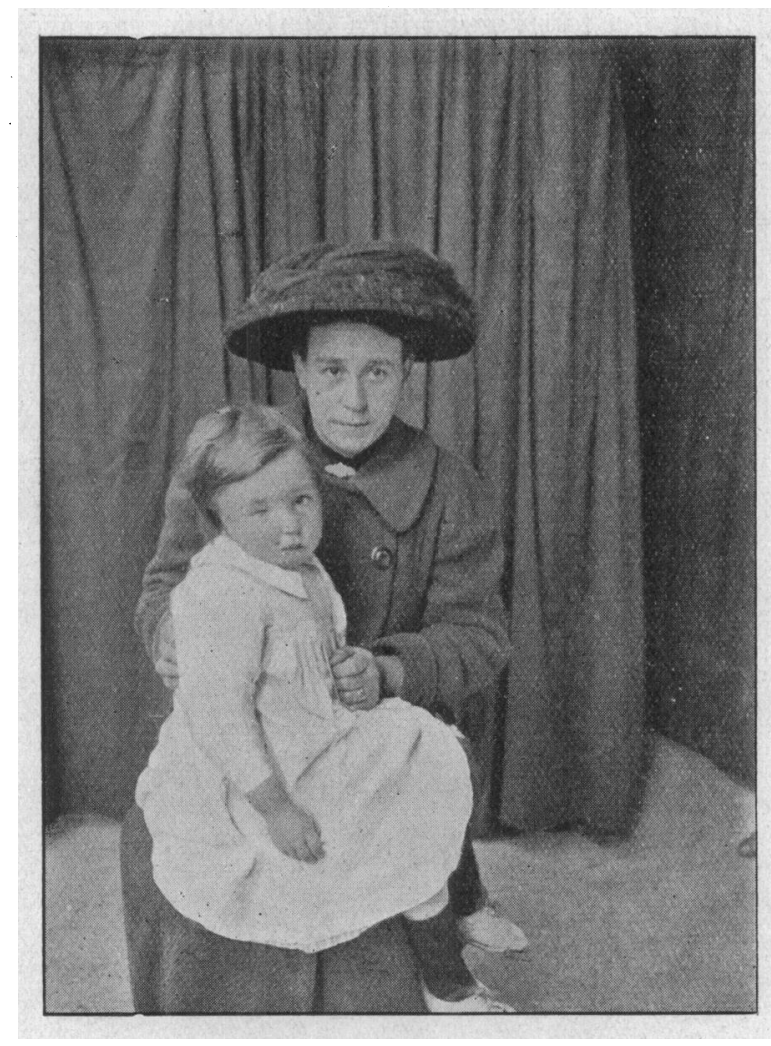

FIG. 2.

branchial cleft. There are no other congenital defects, and the child seems otherwise healthy.

The slight muco-purulent secretion from the right orbit due to conjunctivitis, was soon cured, and the child was lost sight of and could not be traced.

At the beginning of 1914, however, the child was again brought up, and was seen by my colleague, Mr. R. Russell Thomas, to whose courtesy I am indebted for being able again to examine the child, then four years old. The condition had, of course, not changed in any notable degree. The right side of the face had 
grown in proportion with the left, and there was then no very marked facial asymmetry.

The small nodules representing the pinna were now fused into one,. which lay in front of the depression which one may take to represent the external auditory meatus, and the right facial paralysis still existed. It could then also be ascertained that sound was not appreciated on the right side. The two photographs (Figs. 1 and 2) give a fairly good idea of the difference between the two sides of the face.

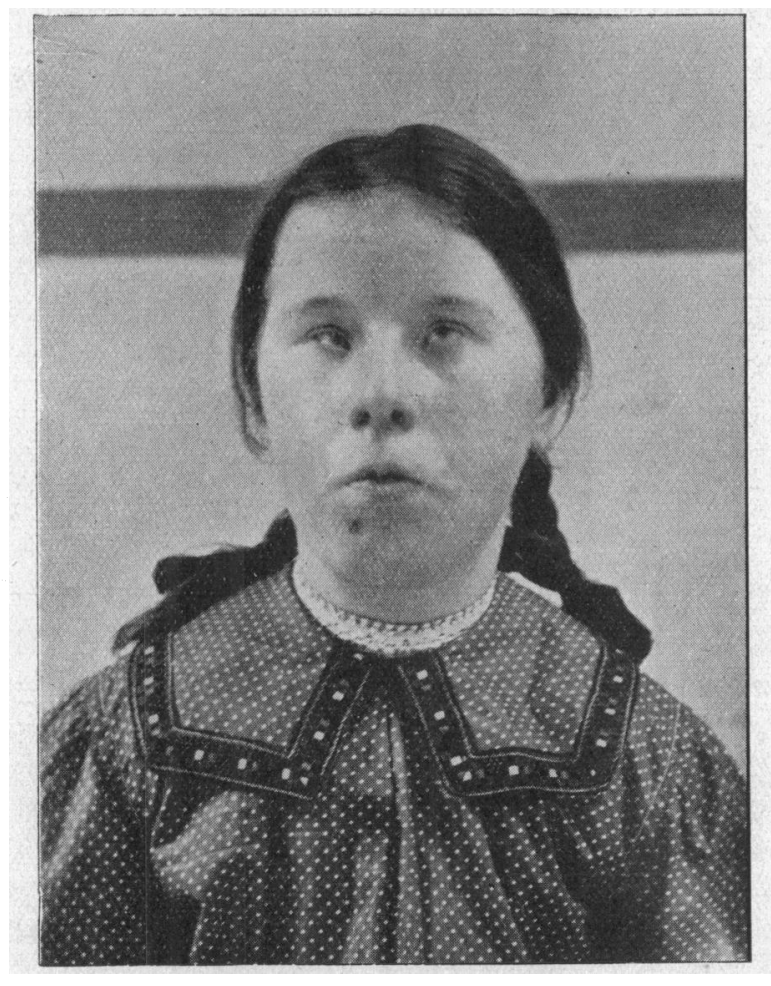

FIg. 3.

CASE 2.-Bilateral microphthalmia.-S. T., at. 13 years. This girl was brought up to my out-patients' department in June, 1914 , to see if glasses would help her. The striking thing about this child was the markedly oblique position of the palpebral fissures, resembling closely the Oriental type. This feature was not present in any of the other children or the parents, who are not of foreign extraction.

Right eye.-This is extremely small, the cornea measuring about 
$7 \mathrm{~mm}$. in diameter. There is a marked and complete coloboma of the iris downwards, with a large coloboma of the choroid.

Left eye.-This is larger than the right, but still undersized, the cornea measuring about $8-9 \mathrm{~mm}$. in diameter. In this eye also there is a complete coloboma of iris, and in the region of the coloboma there is a small amount of uveal pigment on the lens capsule. Again, there is a very large coloboma of the choroid which apparently surrounds the optic nerve head. There is considerable massing of pigment (choroidal) around the margins of the coloboma. She has an internal non-paralytic squint which is bilateral, the eyes looking upwards and inwards, and with this there is marked lateral nystagnus as soon as she tries to look at anything. This renders anything like detailed examination of the fundus impossible, especially in the small right eye. The accompanying photograph (Fig. 3) shows the obliquity of the eyes.

CASE 3.-T. R., at. 8. This boy is of normal physical development but presented malformation of both eyes.

Right eye.-This is undersized. The cornea is small, measuring $7 \mathrm{~mm}$. horizontally and $9 \mathrm{~mm}$. vertically. There is a large coloboma of iris downwards (Fig. 4.) This is associated with a large coloboma of the choroid, also downwards, which involves the optic disc. Vision $6 / 24$ under atropine and with $+3 \cdot 5 \mathrm{D}$.
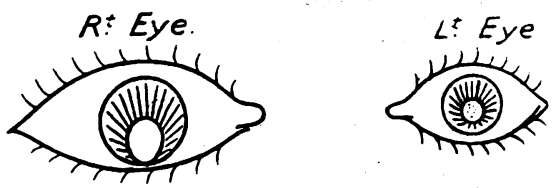

FIG. 4.

T.R. Case 3. Right and left eyes. Actual size of corneæ.

Left eye.-This is definitely microphthalmic, and the palpebral fissure consequently is narrower on the left side than the right. The cornea measures $7 \mathrm{~mm}$. vertically and $5 \mathrm{~mm}$. horizontally (Fig. 4), and there is a coloboma of the iris downwards, which, however, is not complete: that is to say, it does not involve the whole breadth of the iris. There is also a persistent pupillary membrane. On account of this, and the small size of the dilated pupil, it is impossible to get a view of the fundus. The palpebral fissures are both placed somewhat obliquely, particularly the left.

$\mathrm{He}$ is one of a family of four children; the eldest is dead, but none has shown any deformity or malformation. There is no consanguinity in the parents.

CASE 4.-W. H., female, at. 3. She was brought up to hospital on account of a turn in the right eye which had been present since birth. The right palpebral fissure is slightly narrowed, 
the right globe is smaller than the left, and the cornea is noticeably smaller. The pupil is small and inactive, and responds but slightly to atropine. The lens is opaque.' Both irides are blue, but the right iris is paler than the left. There is slight right hemiatrophy of the face. Under atropine, with the slight dilatation that is possible, a faint red reflex can be obtained on the outer side of the lental opacity. The capsule of the lens is densely opaque, but a pyramidal cataract is not present. Corneal measurements : right, $5 \mathrm{~mm}$. transverse diameter; left, $6 \mathrm{~mm}$. transverse diameter. The left eye shows no coloboma of the choroid, or other deformity.

CASE 5.-M. D., at. 9. This is a much less marked case of microphthalmia. The mother states that the child was born with weak eyes; all the other members of the family are normal. There is marked lateral nystagmus, noticed since birth.'

Right eye.-The cornea measures $12 \mathrm{~mm}$. in the vertical by $10 \mathrm{~mm}$. in the horizontal diameter. There is a coloboma of the iris in a downward direction, but not extending to the periphery, and there are to be seen several fine strands of iris tissue, passing on to the lens capsule, representing the remains of a pupillary membrane. There is a marked coloboma of the choroid, involving and surrounding the optic nerve.

Left eye.-The corneal measurements are (vertical and horizontal diameters) $7 \mathrm{~mm}$. There is a complete coloboma of the iris downward, and a coloboma of the choroid equal in extent to that in the right eye. Lens normal.

\section{Remarks}

At first sight, anophthalmia and micropthalmia appear to be very widely differing conditions. However, it is possible to look upon anophthalmia as being of the same type as microphthalmia, but of greater degree, because in the great majority of cases microphthalmia is associated with definite structural defects in the eye, defects which may be regarded as being due to faulty development or actual failure of development. It is therefore probable that they are both dependent on a cause or causes which are more or-less similar in each type of case.

Let us consider the possible causes of the congenital defects on theoretical grounds.

We may place these causes under four headings:-

(a) They may be the result of some inherent defect in the germ plasma itself, or

(b) They may be due to some condition in the environment of the germ cell, either before or after impregnation, which is injurious to its proper growth and development. Similar conditions may exist also in regard to the sperm cell. 
(c) They may also result from inflammatory or degenerative changes occurring at a very early stage in the development of the eye.

(d) Finally, any two or more of these causes may be active in the same case.

These points will now be taken up seriatim :-

(a) Inherent defect in the germ plasma. This point raises the large and much-debated subject of the hereditary transmission of deformities. When we remember that a very large number of the congenital defects of the eyes are but the reappearance in man of conditions which are normal in some of the lower and more primitive states of life, and in view of the fact that there are many well-authenticated cases of transmission of congenital defects from parents to offspring for several generations, sometimes missing one generation to re-appear in the next, the hereditary transmission of disease is an easy and a consoling theory. But the matter is not so simple. In by far the greater number of cases of congenital deformities, no family history of the reappearance of deformities in successive generations is forthcoming. Gross congenital defects are not likely to be forgotten by members of a family, and this point is therefore a valid one. Can it be that in the development of the various parts of the human body there are two forces at work: the one atavistic, tending to the arrest of development at some particular stage and so producing deformity, and the other progressive, stimulating progress towards a higher stage of development ? The latter being the stronger force normal development usually occurs.

Apart from deformities there are, of course, several diseases which show hereditary transmission in a marked degree, i.e., hæmophilia, hereditary optic atrophy, night blindness, and various forms of insanity and mental weakness. We may, in a sense, speak of these as instances of congenital maldevelopment (or deformity) if we look upon the cell groups involved in the particular disease as being badly developed in so far as their function or resistance to external influences is abnormal, i.e., the nerve cells of the retina in retinitis pigmentosa, etc. If we so regard these transmitted diseases the case for hereditary transmission of disease is greatly strengthened. Yet this theory does not stand on a very sure basis, and still requires much confirmation.

(b) Failing this, we must look upon congenital deformities as being accidental, i.e., due to some condition or conditions lying outside the germ plasma and constituting its environment. Amongst these abnormal conditions are to be placed diseases in either parent antecedent to and existing at the time of impregnation of the ovum, such, for instance, as syphilis, tuberculosis, diabetes, etc., or acute diseases, as influenza, rheumatic fever, etc. 
Diseases in the mother, acute or chronic, coming on soon after conception may be held to be a possible cause; but these diseases must be present at a very early stage of development, because by the fourth week of foetal life the invagination of the primary optic vesicle has already occurred; and closure of the choroidal fissure commences about the fifth week.

Perhaps at this point mention may be made concerning the influence of maternal impressions. It is an exceedingly common thing for the mother to attribute the deformity to alleged fright, shock, or accident. The great fault of these statements, however, is that they are always given as having occurred comparatively late in gestation, when all the finer details of development are being succeeded by a stage of growth. We may, therefore, exclude such statements as worthless. . The sight of a deformed person is also credited amongst many women as being likely to cause a deformity in the unborn child of a pregnant woman. Can a strong mental concept have any effect upon the development of the impregnated ovum or the developing foetus? It seems almost foolish to ask the question, for on all grounds such a statement is not in accord with facts, and we know that the strongest of maternal desires has no apparent influence on the determination of sex.

(c) We pass next to the last of the possible causes of congenital deformities of the foetus : antenatal inflammatory and degenerative processes. The histological examination of microphthalmic eyes has led many investigators to make the statement that there are evidences of previous inflammatory processes in such eyes. Others, however, have asserted that they have been unable to find such evidence. So far, then, the question is an open one and by no means yet proven. But even granting that the appearances pointing to a previous inflammation were present in any given case, and they are certainly not present in all, it is still to be proved that they are the cause and not the consequence of the microphthalmia (or other deformity). It is a commonplace of medicine and surgery that any organ which is degenerated, or whose functions are in abeyance, is more prone to inflammatory changes than a healthy sound organ. Perhaps in relation to these groups we may place the effect of amniotic bands in producing deformity. This has been stated to be the cause of some forms of deformity of the eye, as of other parts of the body; but to the writer, the facts in support of this statement are not at all convincing, and need more precise investigation before they can be admitted as being worthy of serious consideration.

This brief résumé shows, then, how little is really known as to the primary factor or factors underlying congenital deformities. The subject is intimately bound up with the whole question of the development of the human impregnated ovum. What is the force 
lying behind the regular division of the cells of the ovum, their division into separate groups and the accurate timing of all these changes ? Much patient work has been expended on the elucidation of these questions and advance has been made, but we have not yet come at the truth, and much research remains to be carried out.

\title{
THE RELATION OF OPHTHALMOLOGY TO THE THEORY OF VISION*
}

BY

\author{
F. W. EDRIDGE-GREEN, M.D., F.R.C.S. \\ OPHTHALMIC SURGEON, SOUTH LONDON RECRUITING AREA
}

IF a theory is not only an explanation but actually true, it ceases to be a theory and becomes what is far more important, a fact.

The theory of vision is as follows :-A ray of light impinging on the retina liberates the visual purple from the rods and a photograph is formed. The rods are concerned only with the formation and distribution of the visual purple, not with the conveyance of light impulses to the brain. The ends of the cones are stimulated through the photo-chemical decomposition of the visual purple by light, and a visual impulse is set up which is conveyed through the optic nerve fibres to the brain. The character of the stimulus differs according to the wave-length of the light causing it. In the impulse itself we have the physiological basis of the sensation of light, and in the quality of the impulse the physiological basis of the sensation of colour. But though the impulses vary in character according to the wave-length of the light causing them, the retinocerebral apparatus is not able to discriminate between the character of adjacent stimuli, not being sufficiently developed for the purpose. This power of discrimination varies with individuals, and hence the different varieties of colour perception which are found.

It is not intended to deal with the overwhelming physiological, physical, and psychological facts in support of the theory, as these have been given elsewhere, many of the facts being so inexplicable that no previous explanation had been attempted. Houstoun $\dagger$ in a very able paper, has completely answered any physical objections which might have been made and has shown that the theory could be deduced from physical facts with the aid of mathematics.

It is the purpose of this paper to show that every possible aberration of function, in accordance with the theory, is represented by a disease of the eye, none of which have hitherto had a satisfactory and accepted explanation.

\footnotetext{
*Paper to be read at the Oxford Ophthalmological Congress, July, 1917.

†Proc. Royal Society, A, Vol. XCII, 1916, p. 424.
} 